\title{
PRIORIDADE DOJUSTO OU SOBERANIA DO BEM?
}

\author{
Claudio Reis \\ U niversidade de Brasília \\ reis@unb.br
}

Resumo: Este artigo pretende discutir al guns aspectos da fil losofia moral contemporânea a partir da maneira como ela reage diante da questão sobreo sentido da vida. 0 título remete para os dois pontos de referência que servirão para delimitar o contexto da filosofia moral contemporânea queéaqui considerado. A primeira referência éum en saio de John Rawls, "The priority of right and ideas of the good", ea segunda é um texto de Iris M urdoch, "The sovereignty of good over other concepts".

Palavras-chave: Sentido da vida, realismo moral, metaética, John Rawls, I ris M urdoch.

M oral philosophycannot avoid takingsides, and would beneutral philosophers merely takesides surreptitiously.

(I ris M urdoch)

M eu objetivo neste texto é refletir sobre o lugar que poderia ocupar a questão sobre o sentido da vida em um certo contexto da filosofia moral contemporânea e o que isso revela sobre a própria filosofia moral. Minha abordagem da questão mesma sobre 0 sentido da vida vai ser, portanto, além de limitada, indireta: interessa-me, sobretudo, ver as implicações da maneira como se põe (ou se deixa de pôr) essa questão para nossa própria compreensão da filosofia moral. O s limites em que se encerra minha abordagem estão referidos no título deste artigo, uma vez que remete para os dois pontos de referência a partir dos quais podemos definir aproximadamente o contexto a que aludi antes. A primeira referência é 0 ensaio de John Rawls "The priority of right and ideas of the 
good", publicado orginalmente em 1988 e em 1993 incorporado ao livro Political liberalism (RAWLS, 1999). A segunda referência é 0 texto del ris M urdoch "The sovereignty of good over other concepts" - originalmente uma conferência pronunciada em 1967 -, publicado em 1970 (MuRDOCH, 1991). A alternativa expressa pelo título de meu texto - prioridade do justo ou soberania do bem - remete ao debate en tre essas duas propostas de abordagem do problema moral. M inha discussão aqui sobre asimplicações da questão sobreo sentido da vida preten de refletir, assim, em última análise, sobre o problema de determinar a abordagem mais adequada do problema moral.

Antes, porém, pareceme necessário dizer al guma coisa sobre o sentido mesmo da questão sobre o sentido da vida. Sobre o que estamos perguntan do quando perguntamos qual éo sentido da vida? 0 que queremos dizer quando dizemos que a vida tem (ou não tem) um sentido? Podemos estar perguntando sobre um telos ou um propósito: que a vida tenha um sentido significa que ela tem um propósito. Isso ainda pode ser entendido de duas maneiras: uma vida com sentido é aquela que se dirige a esse propósito ou se orienta por el e ou, alternativamente, é aquela que realiza ou produz aquilo que éo seu propósito. Em ambos os casos, o propósito é al go externo à própria vida. M as se quisermos agora evitar as referências teleológicas, podemos entender a pergunta sobre o sentido da vida como sendo a pergunta sobre o que constitui a vida que vale a pena, não a relativa a quetipo de propósito deve orientar-nos ou devemos tentar realizar, mas que tipos de coisas devemos reunir e manifestar em nossas vidas para que possamos percebêlas como dotadas de sentido.

De todo modo, há algo em comum a essas duas maneiras de entender a questão: há sempre uma remissão ao problema do valor. Seja como for que se prefira entender a questão sobre o sentido da vida, gostaria de tomá-la aqui como uma questão sobre o que dá valor à vida, de modo que a distinção entre uma vida com sentido e outra sem sentido seja uma distinção valorativa. A questão que me interessa mais diretamente, enfim, não é a questão geral sobre 
o sentido da vida, mas a questão mais restrita sobre o sentido de uma ou desta vida em particular. Não me importa tanto saber se podemos dar uma resposta à questão geral sobre o sentido da vida, mas, sim, saber o que envolve a possibilidade de distinguir entre uma vida com sentido e outra sem sentido.

A maneira com proponho entender a questão sobre o sentido da vida parece-me compatível, em linhas gerais, com a proposta expressa por Julio Cabrera em seu texto "Sentido da vida e valor da vida: uma diferença crucial". Concordo com Cabrera quando distingue a questão sobre o sentido da vida da questão sobre o seu valor. Estou ainda de acordo com o corolário dessa distinção, que dizque a primeira questão não tem um interesse filosófico especial, enquanto a segunda tem. N ossas diferenças começam a surgir quando Cabrera inicia seu desenvolvimento sobre a questão do valor da vida, questão que, concordamos, é a mais interessante do ponto de vista filosófico. A qui não é o lugar para desdobrar essas diferenças, que constituem, em última análise, uma crítica à sua concepção de ética negativa. Limito-me a enfatizar um ponto que me parece importante porque esclarece a maneira como entendo a questão sobre o sentido da vida neste artigo.

A o contrário de C abrera, a questão que me parece de maior relevância filosófica não é a questão geral sobre o valor da vida, mas a questão (mais limitada, tal vez, da perspectiva da ética negativa) sobre o valor de uma vida ou desta vida em particular (com uma possível versão mais geral que falaria não de "vida", mas de "modo de vida"). C abrera claramente põe a questão geral sobre o valor da vida como prévia ou, mesmo, prioritária com relação à questão mais particular sobre o valor de uma vida, o que é uma decorrência de sua distinção entre "estrutural" e "intramundano" (que aproxima da distinção entre "ontológico" e "ôntico", da "diferença ontológica", tal como entendida na tradição heideggeriana). Não aceito essa prioridade e vejo como problemática a relevância de qualquer resposta à questão geral sobre o valor da vida para uma consideração da questão particular sobre o valor de uma vida (talvez porque, como 
os filósofos citados no texto de Cabrera, não consiga "tematizar a diferença ontológica"). De todo modo, Cabrera reconhece a independência relativa que a questão sobre se vale a pena ou não viver a vida (eu preferiria a questão sobre que tipo de vida vale a pena ser vivida) tem com relação a uma resposta, afirmativa ou negativa, sobre o val or da vida em geral. É no domínio dessa questão (ou seja, que tipo de vida vale a pena ser vivida, o que implica poder distinguir entre uma vida com valor e outra sem valor) que estarei me movendo.

Enten dida dessa maneira, a questão sobre o sentido da vida é uma questão sobre os valores mais altos, ou seja, aqueles val ores aos quais todos os aspectos da minha vida devem estar referidos, se minha vida deve ter sentido ou valor (ou deve valer a pena). Refletir sobre a questão do sentido da vida, portanto, implica ou envolve refletir sobre os valores - sobre sua natureza e sua origem, sobre a maneira como os conhecemos, descobrimos ou criamos. U ma boa parte, assim, da dificuldade que al guns encontram em lidar com a questão sobre o sentido da vida explica-se pela dificuldade de lidar com o problema do valor em geral. Esse é, podemos dizer, um dos temas do célebre ensaio de D. W iggins "Truth, invention, and the meaning of life". Está presente também no texto de Iris M urdoch, que é uma das referências deste artigo. Mais uma vez, apenas tangencio esse tema fundamental para prender-me ao aspecto que me interessa discutir mais de perto aqui: o de destacar um efeito ou, talvez melhor, um sintoma dessa dificuldade.

Comecemos considerando duas histórias propostas por G erald G aus para introduzir uma distinção, para ele, importante:

A) A If éum empregado de uma loja especializada em figurinhas de lutadores profissionais de luta-livre; ele passa a maior parte de seu tempo livre comendo pizzas e assistindo ao canal 24 horas de luta-ivre na TV a cabo. Betty conhece Alf desde a infância e acha que isso é um terrível desperdício; Alf é altamente inteligente e poderia ter uma vida marcada por uma variedade de atividades interessantes e valiosas. U m dia Betty 
decide que não pode mais ficar calada; ela diz a Alf que ele está desperdiçando sua vida. Betty tenta mostrar para Alf que ele poderia cultivar outros interesses e aperfeiçoar a si mesmo. U ma vida de prazeres estúpidos, ela diz, simplesmente não é boa o bastante. Em resposta, Alf diz que está satisfeito com sua vida simples. M as, diz Betty, estar satisfeito não éo bastante. [Betty lembra a passagem do U tilitarismo, de Mill, em que ele afirma ser melhor ser Sócrates insatisfeito do que um porco satisfeito]. Nem mesmo Mill dissuade Alf de sua vida de prazeres estúpidos. "Se você quer ser desagradável", ele diz, "prefiro ser um porco feliz assistindo luta-ivre do que Sócrates lendo filosofia. Por que você não cuida da sua própria vida?"

B) Charlie trabal ha com Alf na loja de figurinhas. Ele percebe que sempre que Alf está trabalhando algum dos outros empregados parece "perder" alguma coisa. Às vezes somem alguns dólares, às vezes um relógio, às vezes uma figurinha especialmente valiosa. C harlie suspeita de Alf, mas fica quieto até 0 dia em que 0 vê olhando na carteira de D oris e tirando dez dólares, que ela mais tarde diz estarem faltando. C harlie confronta Alf: "O que você tem a dizer em sua defesa, seu ladrão?!". A resposta de Alf é surpreendente: "Sim, eu roubei, mas estou feliz em ser um ladrão, portanto, cuide de sua própria vida". (G Aus, 1999, p. 3-4)

Em ambas as histórias, diz G aus, al guém diza Alf que ele não deveria fazer o que está fazendo, e sua resposta em cada caso é a mesma. M as, continua $\mathrm{G}$ aus, a resposta de AIf na primeira história é, para muitos, intuitivamente mais aceitável do que a da segunda. Isso sugere uma distinção entre duas maneiras de julgar o que se deve ou não fazer, o que implica uma separação entre dois domínios de questões e, complementarmente, uma diferença na forma de tratar cada uma delas.

Essa distinção éfeita por toda uma vasta linhagem de filósofos morais contemporâneos, freqüentemente baseados nas mesmas intuições que estão na origem das histórias de $\mathrm{G}$ aus. ${ }^{1} \mathrm{U}$ m dos que 
põe mais claramente o que está em jogo nessas distinções é Richard H are (1963), ao sugerir que há, no campo mais amplo das questões morais, dois subconjuntos de questões: as que dizem respeito a interesses (ou, talvez mais precisamente, a conflitos de interesses) e as que dizem respeito a ideais. $\mathrm{H}$ are acredita que seu prescritivismo, baseado em sua análise da linguagem moral, permite ver, para além dessa distinção, um ponto mais interessante: cada um desses subconjuntos de questões está sujeito a modos distintos de argumentação. N ão se argumenta sobre ideais da mesma forma como se argumenta sobre conflitos de interesse. Embora em ambos os domínios façamos juízos de valor, sujeitos aos princípios da prescritividade e, sobretudo, da universalizabilidade tal como entendidos genericamente por ele, no domínio dos ideais não há lugar para o tipo específico de raciocínio que $\mathrm{H}$ are chama de "argumentos do tipo regra de ouro" (golden-rule arguments, que consistem, simplificadamente, em um teste de "inversão de papéis"). M as se não há lugar para esse tipo de raciocínio, não haveria lugar para outros? H are (1963, p. 150-151) diz:

Pode-se perguntar, já que argumentos do tipo regra de ouro não têm lugar aqui, se não há outros argumentos que poderiam ser relevantes para tais questões. Isso pode depender do que estamos dispostos a contar como um argumento; no entanto, isso não é apenas uma questão terminológica. Há certamente argumentos que seriam cogentes em tal caso, se as partes já aceitassem al gum ideal de excelência humana; fatos poderiam ser aduzidos para mostrar que tal e tal linha de conduta estariam ou não de acordo com o ideal. [...] Há também argumentos que tentam mostrar a inconsistência de duas opiniões morais que al guém afirma sustentar. [...] No entanto, é impossível, efilósofos morais não deveriam tentar encontrar métodos de argumentação que resolvessem, definitivamente, disputas entre seguidores de ideais diferentes em todos os casos.

Em suma: no que diz respeito às questões que envolvem conflitos de interesses, podemos ter a esperança de encontrar um 
modo de resolvê-las argumentativamente, graças à lógica dos conceitos morais, se aceitamos a sugestão de $\mathrm{H}$ are. $\mathrm{N}$ o que diz respeito aos ideais, no entanto, uma vez surgido algum desacordo, estamos fadados ao desentendimento perpétuo, assumindo que a saída argumentativa seria a saída aceitável. Tudo isso pode muito bem estar embebido daquilo que Bernard W illiams chamou de "concepção racionalista da racionalidade", resultante de al gumas

características sociais do mundo moderno, que impõem à deliberação pessoal e à idéia mesma de razão prática um modelo saído de uma compreensão particular da racionalidade pública. Essa compreensão requer, em princípio, que toda decisão repouse sobre fundamentos suscetíveis de receber uma explicação argumentada. (W ILlıAms, 1985, p. 24)

D evo dizer, no entanto, que, apesar da sugestão implícita de W illiams de que essa compreensão particular da racionalidade pública esteja pelo menos em parte equivocada (sugestão que deveria ser mais bem examinada), e de não considerar a resposta de $\mathrm{H}$ are como totalmente adequada, penso terem aquelas intuições que estão na base da distinção entre os dois domínios de questões alguma plausibilidade inicial (suficiente, pelo menos, para não as descartarmos preliminarmente). Essa plausibilidade inicial, a meu ver, está associada à idéia de justificação. Mais particularmente à idéia de que, na moralidade, é incontornável uma certa exigência de justificação, facilmente associada às questões do tipo da segunda história de $\mathrm{G}$ aus ou às relativas a interesses de $\mathrm{H}$ are. $\mathrm{O}$ problema que põe a reflexão sobre a questão sobre o sentido da vida é justamente se essa exigência (ou al go semelhante a ela) pode ou deve ser estendida também ao domínio próprio a que pertence essa questão (e, no caso de uma resposta afirmativa, como seria essa extensão e o que ela implicaria em termos de epistemologia e ontologia morais). 0 problema é saber se podemos (e como poderíamos) tratar das questões referentes aos valores mais altos - ao que nos permite distinguir entre uma vida com sentido e outra sem sentido - de 
modo a honrar, também aí, se não uma "exigência", ao menos uma possibilidade de justificação que faria com que tivéssemos algum tipo de réplica à resposta de Alf na primeira história de G aus.

Passemos, então, a Rawls. Antes de mais nada, é preciso lembrar que o problema que interessa a Rawls éum problema muito particular. Ele próprio o en uncia de forma sucinta: "C omo é possível existir, ao longo do tempo, uma sociedade justa e estável de cidadãos livres e iguais, mas que permanecem profundamente divididos por doutrinas religiosas, filosóficas e morais razoáveis?" (R AWLS, 1996, p. 4). Seu problema é o de encontrar uma concepção de justiça suficientemente robusta para constituir o foco de um consenso em um contexto caracterizado pelo pluralismo. N ão estou aqui interessado em discutir esse problema particular da justiça. Também não se constitui em dificuldade para mim aqui o aspecto muito específico do problema. Importa sobretudo a maneira como o problema é posto e o modo proposto para resolvêlo.

Há, na formulação do problema, uma referência implícita ao consenso em torno da concepção de justiça que permitiria a existência, ao longo do tempo, de uma sociedade justa e estável, assim como há uma referência explícita ao desacordo que caracteriza as sociedades marcadas pelo fato do pluralismo. A solução proposta por R awls a esse problema, assim posto, pede que se introduza uma distinção, semelhante à que já vimos em G aus e H are, entre dois domínios de questões. 0 sucesso da resposta de Rawls ao problema que 0 interessa depende em grande parte do bom êxito em isolar, do conjunto de questões indefinidamente abertas ao desacordo, um outro conjunto de questões passíveis de uma abordagem conducente ao consenso. De um lado, há o domínio de questões que dizem respeito às concepções de bem, às variadas maneiras de definir substantivamente o que seja uma boa vida ou o que dá valor à vida humana etc. (é o domínio do que R awls chama de doutrinas abrangentes). De outro, há o conjunto de questões que dizem respeito aos requisitos necessários para a associação política ou, se quisermos 
generalizar um pouco mais, que dizem respeito "ao que devemos uns aos outros", para usar a expressão de Thomas Scanlon. ${ }^{2}$

Esses dois domínios de questões - das questões sobre o justo e das questões sobre o bem - podem ser, em certa medida, relacionados, respectivamente, aos domínios tradicionalmente chamados de público e privado. As questões sobre o justo surgem e se resolvem no domínio público, enquanto as questões sobre o bem têm lugar no domínio privado. 0 tipo de abordagem apropriado para as questões sobre o justo é caracterizado por uma razão pública e pela busca de uma justificação pública. E o que caracteriza, por sua vez, essa justificação pública? "Justificação" em geral significa, para Rawls (1999, p. 508),

argumento dirigido àqueles que discordam de nós ou a nós mesmos quando temos opiniões divergentes. Pressupõe um choque de visões entre pessoas ou de visões de uma mesma pessoa, e busca convencer os outros, ou a nós mesmos, da razoabilidade dos princípios sobre os quais nossas reivindicações e juízos baseiam-se. Por visar à reconciliação pela razão, a justificação parte daquilo que todas as partes envolvidas aceitam em comum.

Justificação, portanto, é um tipo de argumento que surge diante de uma situação de desacordo, buscando superá-la a partir de um acordo ou consenso mínimo. Em uma sociedade bem ordenada, esse consenso mínimo éuma concepção pública de justiça. U $m$ argumento que parta dessa concepção pública de justiçaé, assim, um argumento de justificação pública. Em questões de justiça, portanto, podemos esperar alcançar uma resolução argumentada ou justificada dos conflitos ou desacordos - desde, é claro, que possamos chegar a um consenso sobre qual é a melhor concepção de justiça (o que Rawls pensa ser possível: é o sentido de seu argumento contratualista, a partir da posição original).

Passemos agora à perspectiva do outro domínio de questões ou seja, às questões do domínio "privado", relativas às concepções 
abrangentes de bem. Do ponto de vista "interno" dessas doutrinas abrangentes, que incluem nossa concepção do que dá sentido a nossas vidas, podemos certamente falar de justificação no sentido geral. Supondo-se que compartilhamos com alguém uma concepção do que torna nossa vida valiosa, podemos agora conceber a possibilidade de superação deum desacordo como resultado de uma argumentação, partindo justamente da concepção que partilhamos. Se o desacordo surge no nível da própria concepção sobre o que dá sentido à vida, então a "reconciliação pela razão" que ocorre por meio da justificação exigiria que tivéssemos algum ponto de vista comum, análogo, talvez, ao ponto de vista da posição original no caso da concepção dejustiça, quenos permitisse dizer qual éa melhor concepção abrangente de bem. ${ }^{3} \mathrm{Q}$ uanto a isso, Rawls é cético: sobre qual seja a melhor concepção do que seja bom em geral não há reconciliação possível (é o que procura ao menos explicar com as idéias de pluralismo razoável e de limites do juízo).

$\mathrm{Na}$ perspectiva de Rawls, podemos dizer que nossos juízos políticos (nossos juízos sobre a justiça) estão justificados em relação a uma determinada concepção de justiça que partilhamos. Podemos também dizer, complementarmente, que a concepção de justiça que compartilhamos está justificada, entendendo por isso que seria ela a escolhida segundo um procedimento de escolha, criado com a intenção de articular al guns de nossos pressupostos fundamentais. No entanto, quando passamos ao domínio das questões sobre 0 bem, aparece uma assimetria importante. Podemos estar pessoalmentejustificados em acreditar que nossa vida tem sentido, do ponto de vista interno de nossa doutrina abrangente; podemos justificadamente dizer de al guém com quem compartilhamos uma concepção que está negligenciando aspectos importantes que confeririam sentido à sua vida. Não poderíamos, no entanto, justificar nossa crença de que sua vida não tem sentido para alguém que não compartilha nossa concepção de bem. I sso poderia ser ampliado: não faz sentido, nessa perspectiva, falar de uma vida justificada, por anal ogia a uma concepção de justiça (publicamente) justificada ou a 
crenças particulares sobre a justiça (publicamente) justificadas. C hegamos, assim, ao mesmo ponto a que H are já havia chegado. A posição de Rawls, evitando a metaética não-cognitivista de $\mathrm{H}$ are e oferecen do uma alternativa viável a seu utilitarismo, pareceme mais adequada einteressante. No entanto, a conclusão neste ponto parece a mesma: no que diz respeito aos ideais ou às concepções de bem, a resposta de Alf permanece incontornável.

Justificar significa apresentar razões. Justificar publicamente exige ainda que as razões apresentadas sejam, em algum sentido, comuns. Por isso não podemos, a partir desse ponto de vista, falar de uma "vida justificada". Falar de uma vida justificada exigiria, segundo Rawls, uma perspectiva comum a partir da qual vidas com sentidos diversos pudessem ser comparadas. I sso é justamente o que a situação de pluralismo parece impedir. E essa situação não é algo contingente, uma infelicidade que poderia, se tivéssemos tido sorte, não ter acontecido. Ela não éuma "condição desafortunada da vida humana" (RawLs, 1996, p. 36 ss e 144 ss). Como resultado do "livre uso da razão prática no contexto de instituições livres", o pluralismo ref lete, em certo sentido, o valor associado a um uso e a um contexto livres. ${ }^{4}$

U ma outra razão, ligada a essa, mas um pouco mais profunda, parece ainda conspirar contra a viabilidade de um lugar para a idéia de uma vida justificada em nossa teoria ética. Essa razão passa por uma certa idéia da racional idade prática e sua relação com os valores. A distinção fundamental entre dois domínios de questões - as relativas ao justo e as relativas ao bem - desdobra-se e amplifica-se no liberalismo político de Rawls, combinando-se com outras. Há, por exemplo, a distinção entre as duas faculdades morais que caracterizam as pessoas vistas como livres e iguais (a capacidade de ter um senso de justiça e a de ter uma concepção de bem (RAwLS, 1996, p. 19 e 81; Raw LS, 2001, p. 18-19). E há também a distinção entre o "razoável" eo "racional" (RaW Ls, 1996, p. 48ss; RaWLs, 2001, p. 6ss). Essas distinções combinam-se entre si: ser razoável está associado à capacidade de ter um senso de justiça, assim como ser 
racional está conectado com a capacidade de ter uma concepção de bem (Raw LS, 1996, p. 52). Ser racional está ligado à capacidade de escolher nossos fins (bem como os meios para realizá-los) e bal anceálos, dando a cada um deles um lugar apropriado em nossas vidas. Ser razoável, podemos dizer, implica estar disposto a aceitar determinados limites à escol ha desses fins, que, como pessoas racionais, buscamos para nós mesmos. Como o próprio Rawls freqüentemente lembra (cf., por exemplo, RAWLs, 1996, p. 25; RAWLS, 2001, p. 81ss.), essas distinções remetem a uma certa interpretação da ética kantiana, especial mente das diferenças entre imperativos hipotéticos e imperativo categórico e da segunda formulação do imperativo categórico. Ele resume essa interpretação da ética kantiana sob o título de "construtivismo". Segundo ele, o construtivismo moral kantiano assume uma noção especial de autonomia - que el echama de "autonomia constitutiva" -, segundo a qual

a ordem de valores morais e políticos deve ser feita ou constituída pelos princípios e concepções da razão prática. [...] A autonomia constitutiva afirma que a assim chamada ordem independente de valores não constitui, mas é ela própria constituída, pela atividade, real ou ideal, da razão (humana) prática ela mesma. (RAwLS, 1996, p. 99)

Rawls é muito cuidadoso ao separar seu liberalismo político, que é, nos seus termos, uma concepção política mais limitada dessa posição kantiana, que é, para ele, uma doutrina abrangente com implicações bem mais fortes do que seria desejável para uma concepção que pretende vir a ser o foco de um consenso. M as não deixa de observar que seu construtivismo político extrai do construtivismo moral kantiano mais ambicioso a idéia de que "os princípios da razão prática originam-se [...] em nossas consciências morais informada pela razão prática" (R AW Ls, 1996, p. 100).

Por trás, enfim, das distinções entre os dois domínios de questões, entre o razoável e o racional e entre as duas faculdades 
morais, está uma hipótese sobre a origem dos valores embutida em uma determinada concepção do agente moral como livre ou autônomo. Há três maneiras, dizRawls, segundo as quais os cidadãos representam-se como livres. Interessa-nos aqui especialmente a primeira:

Cidadãos são livres no sentido de conceberem a si mesmos e aos outros como indivíduos que têm a faculdade moral de ter uma concepção do bem. [...] Como pessoas livres, os cidadãos reivindicam 0 direito de considerar sua própria pessoa independente - e não identificada com - de qualquer concepção específica desse tipo ou do sistema de fins últimos associado a essa concepção. (RawLs, 1996, p. 30; RawLS, 2001, p. 21)

Em suma: nesse estilo de teoria ética está pressuposto que não existe uma ordem independente de valores conhecida ou, de algum modo, apreendida pela razão (teórica), mas toda ordem de valores origina-se, de al gum modo, na atividade da razão (prática). Supor que exista tal ordem independente é não levar suficientemente a sério o fato de que agentes morais são livres ou autônomos. D aí, talvez, a impressão de que, diante da questão sobre o que dá sentido à vida, o chão pareça relativamente mais pantanoso do que quando estamos examinando a questão sobre o que devemos uns aos outros.

É exatamente essa impressão, fundada em tais pressupostos, que Iris M urdoch quer desfazer no texto em que defende a soberania do bem sobre os demais conceitos morais. Referindo-se ao aspecto peculiar da filosofia moral moderna, ela diz:

0 centro desse tipo de filosofia moral póskantiana é a noção de vontade como criadora de valor. Valores que antes estavam em algum sentido inscritos nos céus e garantidos por D eus reduzem-se à vontade humana. Não há realidade transcendente. A idéia de bem permanece indefinível e vazia, de modo que a escolha humana possa preenchêla. 0 conceito moral 
soberano é liberdade, ou possivelmente coragem, em um sentido que a identifica com liberdade, vontade, poder. (MURDOCH, 1991, p. 80-81)

0 recurso à idéia da vontade "nua e orgulhosa", como ela diz, voltada em direção à ação correta ou justa, é um recurso débil diante do desafio posto pela questão "como podemos nos tornar melhores?" - ou, se quisermos, diante da questão "como podemos dar sentido a nossas vidas ou torná-las mais valiosas?" A tentativa kantiana - que deu o tom do tipo de teoria ética de que o liberalismo político de Rawls é um exemplo muito particular - de voltar-se para a razão prática como fonte do valor responde, pensa M urdoch, a um impulso correto: o de tentar encontrar uma resposta para aquelas questões, ultrapassando a "confusão da psique empírica egoísta" (MuRDoch , 1991, p. 83). 0 erro de Kant foi ter olhado no lugar errado: seu erro foi voltar-se novamente sobre o agente, ainda que isolando esse elemento talvez mais elevado que é a vontade como razão prática. U sando, inspirada por Platão, a experiência da beleza e da aquisição de uma competência técnica como analogias, M urdoch sugere uma outra direção:

$N$ as disciplinas intelectuais e na fruição da arte e da natureza descobrimos valor em nossa habilidade de esquecer 0 eu, de ser realistas, de perceber com justeza. U samos nossa imaginação não para escapar ao mundo, mas para juntar-nos a ele, e isso nos estimula por causa da distância entre nossa consciência comum entorpecida e uma apreensão do real. Os conceitos de valor estão aqui patentemente ligados ao mundo, estão estendidos, por assim dizer, entre a mente que busca a verdade e o mundo, não estão movendo-se de um lado para 0 outro por si sós como acessórios da vontade pessoal. A autoridade da moral é a autoridade da verdade, isto é, da realidade. (MURDOCH, 1991, p. 90)

0 que M urdoch aponta em passagens como essa é a inadequação fundamental do tipo de descrição da experiência moral que 
está na base da reconstrução proposta por uma teoria ética como a de Rawls. 0 que ela sugere aqui é que uma resposta teórica incapaz de levar efetivamente a sério essa relação entre valor e mundo, seja lá como devemos entender isso, vai ser necessariamente problemática ou parcial. ${ }^{5} 0$ tipo de distinção entre dois domínios de questões, ponto fundamental para a teoria rawlsiana, por exemplo, com os problemas que carrega, e a ten dência desse estilo de filosofia moral de recolher-se e restringir-se a um dos dois domínios de questões são talvez sintomas, tomando como referência o diagnóstico de M urdoch dessa falha fundamental. De fato, reconhecer a soberania do bem sobre outros conceitos implica reconhecer 0 peculiar "poder unificador" dessa idéia (M U RDOCH, 1991, p. 94). A moralidade, diz M urdoch, mostra-nosum tipo deunidade- unidade que, na cél ebre al egoria platônica, éilustrada na apreensão da idéia de bem. Essa unidade, no entanto, não exclui a complexidade - ao contrário, como também já ilustrava Platão em sua alegoria, à "ascensão" segue-se uma "volta para baixo". D iz M urdoch:

Na medida em que o bem vai ser usado na política e no mercado, deve combinar suas intuições crescentes de unidade com uma progressiva apreensão de complexidade e detalhe. [...] A cena permanece díspar e complexa para além das esperanças de qualquer sistema, e ainda assim, ao mesmo tempo, o conceito de bem espalha-se através de toda ela e lhe dá o único tipo de unidade indistinta e inacabada que ela pode possuir. A área da moral, e portanto a filosofia moral, pode agora ser vista, não como uma questão sorrateira de dívidas e promessas, mas como cobrindo a totalidade de nosso modo de viver e a qualidade de nossas relações com o mundo. (MURDOCH, 1991, p. 96-97)

A dificuldade está agora em passar dessa percepção de inadequação para uma nova proposta de reconstrução de nossa experiência moral. O s desafios - epistemológicos, ontológicos - diante do realista moral não são pequenos. N essa direção, M urdoch, apesar 
de não avançar muito, dá algumas indicações interessantes. Seria conveniente buscar mais esclarecimentos em outras fontes. ${ }^{6}$ Encontrar respostas certas para as questões morais, diz M urdoch, ainda explorando as metáforas platônicas, "é um exercício de justiça e realismo e de realmente olhar". E mais adiante:

C ertamente, virtude é bom hábito e ação conscienciosa. M as a condição de fundo de tal hábito e de tal ação, para os seres humanos, é um modo justo de visão e uma boa qualidade de consciência. É uma tarefa vir a ver o mundo como ele é. U ma filosofia que deixe o dever sem um contexto e exalte a idéia de liberdade e poder como um valor separado de nível mais alto ignora essa tarefa e obscurece a rel ação entre virtude e realidade. A gimos corretamente "quando é chegada a hora" não por força de vontade, mas pelas qualidades de nossas vinculações usuais e com o tipo de energia e discernimento de que dispomos. $\mathrm{E}$ para isso a atividade inteira de nossa consciência é relevante. (MURDOCH, 1991, p. 91-92. Grifo da autora)

Essa tarefa de "vir a ver o mundo como ele é", reconhece Murdoch, é extremamente difícil e, em função disso mesmo, é, certamente, um processo indefinidamente aberto. N ossa apreensão do bem - nossa apreensão daquilo que, finalmente, dá sentido a nossas vidas, dando uma unidade articulada às suas várias partes - é sempre aproximada. ${ }^{7}$ Encontrar uma réplica para Alf é difícil (embora não impossível) porque a resposta vai estar sempre condicionada ao refinamento de nossa apreensão do mundo. E não há, de todo modo, diferença significativa entre a primeira e a segunda situações ilustradas nas histórias de G aus citadas no início destetexto: para a pessoa dotada de discernimento, a razão da inadequação das respostas de Alf nas duas situações vai aparecer como sen do a mesma.

Para concluir, gostaria de tentar sistematizar os pontos que me parecem mais relevantes nessa rápida comparação entre duas abordagens alternativas do problema moral a partir da questão sobre o sentido da vida. Começamos citando duas histórias que ilustram 
uma intuição cuja plausibilidadeinicial reconhecemos. Essa intuição remete à diferença entre dois domínios de questões - questões sobre o que devemos uns aos outros equestões sobre o que confere sentido ou valor a nossas vidas - que pedem tratamento igualmente diferenciado. U m tipo de questão - aquela diz respeito ao que devemos uns aos outros - parece exigir um tipo especial de justificação (uma justificação pública, como sugere Rawls, ou um tipo especial de argumentação como os argumentos do tipo regra de ouro, como sugere $\mathrm{H}$ are). $\mathrm{O}$ outro tipo - aquela que diz respeito ao que dá sentido a nossas vidas - parece dispensar esse tipo de justificação, ou, mesmo, parece não permiti-lo. Essa é uma percepção, na verdade, que está na base da idéia da prioridade do justo: as questões sobre o justo são mais prementes e, tal vez, podem ser mais bem abordadas se separadas das questões intratáveis sobre o sentido da vida. Parece que podemos falar de crenças morais ou juízos morais (do primeiro tipo, ou seja, crenças ou juízos sobre o que é justo), de exigências, de deveres, de obrigações morais justificados de um modo que não nos permite, no mesmo sentido, falar de uma vida justificada.

Diante disso, poderíamos tentar estender a idéia dejustificação de modo que se aplicasse com o mesmo sentido a ambos os domínios. Isso exigiria, no entanto, uma reformulação da idéia de justificação ou da maneira de conceber a argumentação moral tal como aparece nessas teorias (de que são exemplos o liberalismo político de Rawls e o prescritivismo de $\mathrm{H}$ are) que distinguem fortemente os dois domínios. Essa tentativa de estender a idéia de justificação fatalmente levaria à necessidade de superar a distinção entre os dois domínios - e, portanto, de abandonar uma abordagem de nossa experiência moral nos termos propostos por teorias que se servem dela de forma importante. Essa é justamente a aposta de I ris M urdoch e do tipo de realismo moral inspirado por ela.

0 grande apelo de uma posição como a de Rawls é sua promessa de acolher e dar sustentação à idéia de tolerância (no que essa idéia tem de mais positivo). Sua tentativa de lidar com os 
problemas postos pelo fato do pluralismo é, das que conheço, a mais interessante. Rawls promete uma resposta ao problema fundamental da justiça, mas ao preço de uma espécie de ceticismo - que prefere chamar de neutralidade - diante de questões como aquela sobre o sentido da vida. M as, como sugere I ris M urdoch na passagem que escolhi como epígrafe para este texto, "a filosofia moral não pode evitar tomar posição e filósofos morais pretensamente neutros apenas tomam posição sub-repticiamente" (M URD OCH, 1991, p. 78). Talveza idéia de que o justo tem prioridade seja um elemento ou um aspecto de uma determinada concepção mais abrangente, que precisaria ser mais bem articulada.

Termino um pouco inconclusivamente. M inha intenção aqui foi discutir alguns aspectos da fil losofia moral contemporânea a partir da maneira como ela reage diante da questão sobre o sentido da vida. A idéia era a de que pôr essa questão, que parece suficientemente relevante, é um teste interessante para aferirmos a adequação de uma teoria ética no que diz respeito, pelo menos, à maneira como descreve nossa experiência moral. U ma descrição adequada dessa experiência deve dar lugar às questões sobre o valor mais alto, sobre aquilo que dá sentido a uma vida. 0 que parece mais inadequado na idéia da prioridade do justo é, como aponta M urdoch, sua parcialidade, aparente na distinção forte entre dois domínios de questões. N esse sentido, a perspectiva unitária permitida pela idéia da soberania do bem parece mais adequada. 0 desafio que apenas menciono para terminar - é encontrar uma teoria que contemple adequadamente tanto nossa relação com o mundo, como quer o realismo moral sugerido por Murdoch, quanto a relação entre valores e vontade. ${ }^{8}$ Aqui se abre um longo caminho - a ser explorado, talvez, em alguma outra viagem.

ABSTRACT: In this article we discuss some aspects of contemporary moral philosophy by reflecting on how it deals with the question about the meaning of life. The title of the article refers to John Rawls' essay "The priority of right and ideas of the good" and to Iris Murdoch's "The sovereignity of good over other concepts".

Key words: M eaning of life, moral realism, metaethics, John Rawls, I ris M urdoch. 


\section{Notes}

1. Q uase igualmente freqüentes são as críticas dirigidas a esse tipo de distinções e ao que elas implicam. Ver, por exemplo, as críticas de B. W illiams (1985) e de C. Taylor (1989).

2. Ver Reis (2003b).

3. Aqui, mais uma vez, talvez caiba uma crítica de W illiams dirigida ao que el e próprio chama de "reducionismo". Ele diz: "Há uma motivação do reducionismo que não se aplica apenas ao ético e ao nãoético, mas tendea reduzir toda consideração ao elementar. Ela repousa sobre um pressuposto da racionalidade, segundo a qual duas considerações não podem ser avaliadas racionalmente uma em função da outra sem uma terceira consideração comum às duas outras que permita sua comparação. Esse pressuposto é ao mesmo tempo muito forte e perfeitamente infundado" (WILLIAMS, 1985, p. 35).

4. Ver Reis (2003a).

5. Taylor (1989, p. 3) fala no início de seu livro em uma "visão limitada e truncada de moralidade". W illiams (1985) refere-se à moralidade tal como entendida pelo estilo de teoria ética ilustrado por Rawls de "instituição peculiar".

6. Há duas correntes realistas principais na filosofia moral contemporânea. U ma delas, às vezes identificada como "realismo britânico" (McDowell, 1998; PLATTS, 1997; WIGGINS, 1988; DANCY, 1993), teve alguma influência de Murdoch, graças sobretudo ao ensaio sobre a "soberania do bem", que estamos considerando. A outra corrente é às vezes conhecida como "natural ismo americano", representada por nomes como D avid Brink, Nicholas Sturgeon e Peter Railton.

7. Ver Platts (1997, p. 262), comentando justamente essas idéias de Iris M urdoch.

8. As reflexões de W iggins (1988) apontam nessa direção. 


\section{Referêndias}

DANCY, Jonathan. M oral reasons. O xford: Blackwell, 1993.

G aus, G erald. Social philosophy. Armonk: M. E. Sharpe, 1999.

HARE, Richard M. Freedom and reason. O xford: Oxford U niversity Press, 1963.

M CDOWelL, John. M ind, value and reality. Cambridge: Harvard U niversity Press, 1998.

M U RDOCH, Iris. The sovereignty of the good. Londres: Routledge, 1991.

Platts, M ark. Ways of meaning. 2. ed. C ambridge: M IT Press, 1997.

Raw LS, John. Political liberalism. New York: Columbia U niversity Press, 1996.

. Collected papers. Edited by S. Freeman. C ambridge: $\mathrm{H}$ arvard University Press, 1999.

$\overline{1999 .}$

. A theory of justice. Cambridge: Harvard U niversity Press,

- Justice as fairness: a restatement. Cambridge: $\mathrm{H}$ arvard University Press, 2001.

ReIS, Claudio. Pluralismo e verdade. C rátilo: Cadernos do D epartamento de Filosofia da UnB, n. 11, 2003a.

- Liberalismo político e desacordo moral. In: DI NAPOLI, Ricardo et al. (Eds.). Ética \& justiça. Santa M aria: Palloti, 2003b.

TAYLOR, Charles. Sources of the self: the making of the modern identity. C ambridge: Cambridge U niversity Press, 1989.

WIGGINS, David. Truth, invention, and the meaning of life. In: SAYre-M cCord, G. (Ed.). Essays on moral realism. Ithaca: Cornell U niversity Press, 1988.

WILliams, Bernard. Ethics and the limits of philosophy. Londres: William Collins Sons \& C 0., 1985. 